\title{
For more than money: willingness of health professionals to stay in remote Senegal
}

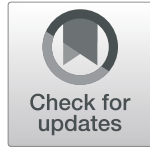

Ayako Honda ${ }^{*}$ (D), Nicolas Krucien ${ }^{2}$, Mandy Ryan², Ibrahima Ska Ndella Diouf ${ }^{3}$, Malick Salla ${ }^{3}$, Mari Nagai ${ }^{4}$ and Noriko Fujita ${ }^{4}$

\begin{abstract}
Background: Poor distribution of already inadequate numbers of health professionals seriously constrains equitable access to health services in low- and middle-income countries. The Senegalese Government is currently developing policy to encourage health professionals to remain in areas defined as 'difficult'. Understanding health professional's preferences is crucial for this policy development.

Methods: Working with the Senegalese Government, a choice experiment (CE) was developed to elicit the job preferences of physicians and non-physicians. Attributes were defined using a novel mixed-methods approach, combining interviews and best-worst scaling (Case 1). Six attributes were categorised as 'individual (extrinsic) incentive' attributes ('type of contract', 'provision of training opportunities', 'provision of an allowance' and 'provision of accommodation') or 'functioning health system' attributes ('availability of basic equipment in health facilities' and 'provision of supportive supervision by health administrators'). Using face-to-face interviews, the CE was administered to 55 physicians (3909 observations) and 246 non-physicians (17961 observations) randomly selected from those working in eight 'difficult' regions in Senegal. Conditional logit was used to analyse responses. This is the first CE to both explore the impact of contract type on rural retention and to estimate value of attributes in terms of willingness to stay (WTS) in current rural post.
\end{abstract}

Results: For both physicians and non-physicians, a permanent contract is the most important determinant of rural job retention, followed by availability of equipment and provision of training opportunities. Retention probabilities suggest that policy reform affecting only a single attribute is unlikely to encourage health professionals to remain in 'difficult' regions. The relative importance of an allowance is low; however, the level of such financial incentives requires further investigation.

Conclusion: Contract type is a key factor impacting on retention. This has led the Senegalese Health Ministry to introduce a new rural assignment policy that recruits permanent staff from the pool of annually contracted healthcare professionals on the condition that they take up rural posts. While this is a useful policy development, further efforts to retain rural health workers, considering both personal incentives and the functioning of health systems, are necessary to ensure health worker numbers are adequate to meet the needs of rural communities.

Keywords: Rural job retention, Human resources for health, Motivation, Incentives, Low- and middle-income countries, Senegal, Discrete choice experiment

\footnotetext{
* Correspondence: ayako-honda@sophia.ac.jp

'Department of Economics, Sophia University, 7-1 Kioi-cho, Chiyoda-ku,

Tokyo 102-8554, Japan

Full list of author information is available at the end of the article
}

(c) The Author(s). 2019 Open Access This article is distributed under the terms of the Creative Commons Attribution 4.0 International License (http://creativecommons.org/licenses/by/4.0/), which permits unrestricted use, distribution, and reproduction in any medium, provided you give appropriate credit to the original author(s) and the source, provide a link to the Creative Commons license, and indicate if changes were made. The Creative Commons Public Domain Dedication waiver (http://creativecommons.org/publicdomain/zero/1.0/) applies to the data made available in this article, unless otherwise stated. 


\section{Background}

The health workforce plays a key role in healthcare service delivery. Equitable distribution of a quality health workforce contributes to ensuring the availability of healthcare services, irrespective of location, and to progressing towards the Universal Health Coverage (UHC) goal by facilitating access to quality healthcare services to all $[1,2]$.

In most countries, the geographical distribution of health workers is skewed towards urban and wealthier areas [3]. While approximately one half of the global population lives in rural areas [4], the rural population are served by only one quarter of the world's doctors and by less than one third of the world's nurses [5]. Inequitable geographical distribution of the health workforce has more severe implications for low- and middle-income countries (LMICs), which suffer from critical shortages of doctors, nurses and midwives [2]. The 36 sub-Saharan African countries bear approximately $24 \%$ of the global burden of disease and have only $3 \%$ of the global health workforce [3].

The inequitable distribution of already inadequate numbers of qualified health workers is a critical barrier to providing health services in LMICs and is often a serious constraint to ensuring fair access to essential health services and achieving health system goals. Links between the number of health workers in a country and both service delivery and health outcomes have been clearly demonstrated $[5,6]$. Consequently, while the issue of geographical health inequity is multidimensional, requiring consideration of both the number of health workers and the quality of services [6], the absolute number of health workers in rural and remote areas in LMICs is low, and concerted efforts are required to address health worker retention in those areas to create a better geographical balance in the distribution of skilled health workers [1].

Senegal is a lower middle-income country, located in sub-Saharan Africa, with a population of 15.9 million [4]. Rural residents accounted for $55.6 \%$ of the population in 2017, slightly decreasing from 58.5\% in 2007 [4]. In Senegal, the physician to population ratio was 0.1 per 1000 people and the ratio for nurses and midwives was 0.3 per 1000 people in 2016 [7]. The figures are lower than sub-Saharan African averages $(0.3$ physicians per 1000 people; 1.1 nurses and midwives per 1000 people in 2016) and countries with a similar economic status (1.6 physicians per 1000 people; 2.3 nurses and midwives per 1000 people in 2016) [8]. The shortage of health workers is even more severe in rural Senegal [9]. In 2012, 66\% of all physicians in Senegal (667 of 1011 physicians) were located in the Dakar region, which houses the nation's capital [5], while $76 \%$ of the population live outside Dakar [4]. In addition to the geographical inequitable distribution of inadequate numbers of health professionals, Senegal's health system also suffers from widespread health professional absenteeism and poor-quality healthcare services [10].

Over the past decade, the Senegalese Health Ministry has made efforts to address the inequitable distribution of qualified health professionals, including the introduction of measures to improve posting and recruitment processes for health workers in rural and remote areas [9]. Currently, the Senegalese Government is developing policy that aims to encourage health professionals to remain in rural posts, particularly in areas that the Government defines as 'difficult' regions. The Human Resources Department of the Senegalese Health Ministry has a working definition of 'difficult' regions which includes geographical areas that constrain professional, personal and family growth and are characterised by a set of geographical, security, infrastructure and social service criteria [11]. While there is political momentum to improve conditions for those in 'difficult' regions, the Government is restricted by poor resource availability and hopes to identify priority areas for reform. This study determines how different aspects of working conditions encourage health workers to stay in rural areas.

\section{Methods}

The study employed the choice experiment (CE) methodology. This approach is increasingly used to elicit health preferences in a range of areas [12], including health worker preferences [13]. CEs ask individuals to state preferences for hypothetical alternatives, each described by several attributes. They are a favoured technique in preference research because they allow estimation not just of what is important, but how important it is. By asking individuals to make trade-offs between attributes, and analysing responses in a random utility framework, researchers can estimate marginal rates of substitution between attributes (MRS; how much of one attribute is needed to compensate for the reduction in another attribute) and the probability accepting a given job.

This study extends the current literature applying CE to job choices in LMICs in two ways. Firstly, a novel mixed-methods approach was used to develop attributes and levels, combining interviews with a best-worst scaling (BWS) (Case 1) experiment. This is the first study to use the BWS (Case 1) method to reduce the number of attributes to a manageable level. Secondly, a 'period of assignment' attribute was included to estimate trade-offs, allowing the influence of other attributes on intended time in a post to be determined. To the authors' knowledge, this is the first study to include such an attribute to estimate trade-offs. 


\section{Defining attributes and levels}

A novel two-stage approach was used to develop attributes and levels. Interviews were first undertaken with 176 healthcare professionals working in remote, rural and urban areas (31 physicians, 94 nurses, 51 midwives) to explore factors influencing the retention of healthcare professionals in rural posts [14]. In-depth interviews with eight health administrators in the Senegalese Health Ministry were also undertaken. Thematic analysis identified an initial list of factors that motivated or demotivated healthcare workers in rural areas. The factors were categorised as pre-service and in-service education, regulatory systems, financial and non-financial incentive schemes and professional and personal support. Subsequent analysis identified 14 factors that influenced the retention of healthcare professionals in rural posts.

A BWS (Case 1) approach [15, 16] was used to reduce the 14 attributes to a manageable number for use within a CE (5-7 attributes) [12]. Respondents to the BWS study were 266 health professionals, comprising 170 nurses, 68 midwives and 28 clinicians working in the 'difficult' regions of Senegal. Locally trained interviewers administered the best-worst tasks using face-to-face interviews. Respondents were given 14 best-worst tasks (Fig. 1). In each task, respondents were asked to select the attributes that were most and least likely to influence their decisions to stay in rural posts.

The BWS data were analysed using both count and choice analysis, and the results were compared to confirm validity $[15,16]$. The results from the count analysis are shown in Table 1 . The choice analysis results were consistent with the count analysis and are available from the authors upon request. Items ranked highly in the BWS were proposed for inclusion in the CE, with careful consideration given to whether the items were relevant to both policy and the working conditions of physicians and non-physicians in Senegal. Specifically, the five most valued items in the BWS were considered for inclusion as attributes in the CE. A series of discussions with team members who were experienced in data collection helped to clarify and refine the items from the BWS for use in the CE. For example, 'support for career development' used in the BWS was discussed in the context in Senegal to develop an implementable policy action, and re-defined as 'provision of training opportunities' (the detailed definition of a training opportunity is provided in Table 2). Also, as discussed later in this section, the inclusion of the period of assignment attributes was discussed together with the BWS results to establish the final set of attributes. Discussion with the Health Ministry assisted in the finalisation of the attributes and levels (Table 2) for use in the CE.

The CE attributes were classified as factors relating to (1) individual (extrinsic) incentive benefits (type of contract, provision of training opportunities, provision of an allowance, and provision of accommodation) and (2) functioning of health systems (availability of basic equipment in health facilities and provision of supportive supervision by health administrators). As the working conditions for physicians and non-physicians can be diverse, including in the types of allowance provided (e.g. physicians receive a skills-based allowance, non-physicians receive a rural allowance), different CEs were given to each group of healthcare workers.

Most CEs eliciting job preferences use a salary attribute to determine how much health workers need compensating to accept a reduction in working conditions, i.e. working in a rural rather than urban location [17]. However, discussions with local interviewers and staff in the Senegalese Health Ministry revealed that salary-related questions were culturally sensitive and could make respondents feel uncomfortable and reluctant to respond to the survey. Furthermore, the Health Ministry did not plan to increase the salaries of health professionals, except through the provision of a rural allowance. Consequently, we used an assignment period attribute, number of years of assignment

\begin{tabular}{|c|c|c|}
\hline \multicolumn{3}{|l|}{ Q 3.2} \\
\hline Items & $\begin{array}{c}\text { Most likely to } \\
\text { influence }\end{array}$ & $\begin{array}{l}\text { Least likely to } \\
\text { influence }\end{array}$ \\
\hline \multicolumn{3}{|c|}{ Management of human resources at the regional level } \\
\hline \multicolumn{3}{|c|}{ Guaranteed access to utilities at health facilities } \\
\hline \multicolumn{3}{|c|}{ Guaranteed access to drugs at health facilities } \\
\hline \multicolumn{3}{|l|}{ Provision of professional support } \\
\hline Financial incentive (based on skills) & & \\
\hline
\end{tabular}

Fig. 1 Example of best-worst task 
Table 1 Count analysis of best-worst data at a sample level

\begin{tabular}{|c|c|c|c|c|}
\hline Item & Best & Worst & Ratio score & Rescaled ratio score \\
\hline Improved professional mobility & 124 & 365 & -0.540 & 0.189 \\
\hline Management of human resources at the regional level & 97 & 410 & -0.721 & 0.077 \\
\hline Promote participation in social events & 251 & 297 & -0.084 & 0.470 \\
\hline Development of inter-professional exchange & 69 & 375 & -0.846 & 0.000 \\
\hline Help to get scholarship & 195 & 365 & -0.313 & 0.328 \\
\hline Help to get public contract & 596 & 126 & 0.777 & 1.000 \\
\hline Provision of professional support & 272 & 227 & 0.090 & 0.577 \\
\hline Financial incentive (based on distance) & 644 & 177 & 0.646 & 0.919 \\
\hline Financial incentive (based on skills) & 273 & 403 & -0.195 & 0.401 \\
\hline Provision of accommodation & 316 & 220 & 0.181 & 0.633 \\
\hline Guaranteed access to medical equipment & 345 & 169 & 0.357 & 0.741 \\
\hline Guaranteed access to drugs & 140 & 154 & -0.048 & 0.492 \\
\hline Guaranteed access to utilities & 146 & 223 & -0.212 & 0.391 \\
\hline Support of career development & 258 & 214 & 0.094 & 0.579 \\
\hline Individuals & 266 & & & \\
\hline Best & $3726 / 3738$ & & & \\
\hline Worst & $3725 / 3738$ & & & \\
\hline
\end{tabular}

Table 2 Attributes and levels

\begin{tabular}{|c|c|c|c|c|}
\hline Attribute & Category & Definition & $\begin{array}{l}\text { Regression } \\
\text { labels }\end{array}$ & Levels \\
\hline $\begin{array}{l}\text { Period of } \\
\text { assignment }\end{array}$ & Individual benefits & $\begin{array}{l}\text { The total number of years of } \\
\text { assignment to a rural/remote } \\
\text { job }\end{array}$ & PERIOD & $\begin{array}{l}\text { 1. } 2 \text { years } \\
\text { 2. } 4 \text { years } \\
\text { 3. } 6 \text { years } \\
\text { 4. } 8 \text { years }\end{array}$ \\
\hline Allowance & Individual benefits & $\begin{array}{l}\text { Provision of skills/ } \\
\text { qualification-based allowance } \\
\text { or rural/remote job allowance }\end{array}$ & ALLOWANCE & $\begin{array}{l}\text { 1. No allowance } \\
\text { 2. Rural job allowance provided } \\
\text { 3. Skill-based allowance provided } \\
\text { (for physicians) }\end{array}$ \\
\hline Equipment & $\begin{array}{l}\text { Functioning of } \\
\text { health system }\end{array}$ & $\begin{array}{l}\text { Availability of equipment at } \\
\text { the health facility that allows } \\
\text { the provision of a basic } \\
\text { package of health care services }\end{array}$ & EQUIP & $\begin{array}{l}\text { 1. Inadequate: Medical equipment at the facility does } \\
\text { not allow the provision of a basic package of health services } \\
\text { 2. Adequate: Medical equipment at the facility allows } \\
\text { the provision of a basic package of health services }\end{array}$ \\
\hline Accommodation & Individual benefits & $\begin{array}{l}\text { While working in a rural area, } \\
\text { the employer provides free } \\
\text { accommodation that is } \\
\text { appropriate for marital/family } \\
\text { status }\end{array}$ & ACCOMMOD & $\begin{array}{l}\text { 1. No provision of accommodation } \\
\text { 2. Accommodation provided }\end{array}$ \\
\hline $\begin{array}{l}\text { Types of } \\
\text { contract }\end{array}$ & Individual benefits & $\begin{array}{l}\text { Either permanently contracted } \\
\text { government workers, } \\
\text { temporary contract with } \mathrm{MoH} \text {; } \\
\text { temporary contract with } \\
\text { health facilities; or temporary } \\
\text { contract with local authorities }\end{array}$ & CONTRACT & $\begin{array}{l}\text { 1. Permanent: permanently contracted government workers } \\
\text { 2. Temporary (MoH): Temporary appointment by } \mathrm{MoH} \\
\text { 3. Temporary (Health facility): Temporary appointment by } \\
\text { health facilities } \\
\text { 4. Temporary (Local): Temporary appointment by local } \\
\text { authorities }\end{array}$ \\
\hline $\begin{array}{l}\text { Training } \\
\text { opportunities }\end{array}$ & Individual benefits & $\begin{array}{l}\text { Provision of further training } \\
\text { offered outside the work place } \\
\text { (excluding further education } \\
\text { for degree purposes) }\end{array}$ & TRAINING & $\begin{array}{l}\text { 1. No provision of training opportunities } \\
\text { 2. Training opportunities provided }\end{array}$ \\
\hline $\begin{array}{l}\text { Support } \\
\text { (for non- } \\
\text { physicians) }\end{array}$ & $\begin{array}{l}\text { Functioning of } \\
\text { health system }\end{array}$ & $\begin{array}{l}\text { Either no support; supportive } \\
\text { supervision by health } \\
\text { administrators; or clinical } \\
\text { advice and support from peer } \\
\text { health professionals }\end{array}$ & SUPPORT & $\begin{array}{l}\text { 1. No support } \\
\text { 2. Managerial support: Supportive supervision by health } \\
\text { administrators } \\
\text { 3. Clinical support: Clinical advice and support from peer } \\
\text { health professionals }\end{array}$ \\
\hline
\end{tabular}


to a rural post, to determine the 'willingness to stay' (WTS, i.e. how long health workers would stay in difficult areas if certain working conditions were improved). To the best of our knowledge this approach has not been previously employed in LMICs.

\section{Defining choice tasks}

A D-efficient design was used to identify the choice tasks to present to respondents. This approach minimises the standard errors (SEs) of parameters [18], thus ensuring more precise parameter estimates. Assuming null interaction effects between attributes (i.e. the preferences for one attribute do not depend on the level of another attribute) and using non-informative priors (no a priori information on preference parameters), the approach generated 15 choice tasks for physicians and 16 choice tasks for non-physicians. Each choice task presented two rural job options and asked respondents to choose their preferred option. A subsequent question asked if they would prefer to remain in their current position rather than take up the chosen option (opt-out response). Figure 2 presents an example choice task. The questionnaire also collected information on socio-demographic characteristics of respondents. A copy of the questionnaire is available from the authors upon request.

\section{Sample, setting and data collection}

The study elicited the job preferences of physician and non-physician health workers (specialised nurses, nurses and midwives). Data collection took place in the eight 'difficult' regions of Senegal (of a total of 14 regions). Using the Health Ministry's human resources database, participants were randomly selected from a list of physician and non-physician health professionals working in clinics and hospitals in the regions of interest. If a pre-determined health professional was unavailable, or had been transferred, a health worker of the same professional type and at the same health facility was substituted in their place. Louviere et al's [19] sample size calculator determined that a minimum of 42 physician and 44 non-physician participants was necessary for the study (choice probability $=40 \%$, confidence level $=$ $95 \%$, accuracy level $=90 \%$, attrition rate $=10 \%$, number of tasks $=15$ or 16 ).

Face-to-face interviews were used to collect data [20]. A locally trained team of 10 interviewers and two field coordinators collected the data. Prior to the commencement of data collection, the questionnaire was pilot tested on 16 respondents in two health centres. After the pilot testing, the definitions of some attributes were changed and the levels of some attributes revised.

\section{Choice question 3}

\begin{tabular}{|lr|}
\hline \multicolumn{2}{|c|}{ Rural Job A } \\
\hline $\begin{array}{l}\text { Period of } \\
\text { assignment }\end{array}$ \\
\hline $\begin{array}{lr}\text { Provision of a rural } \\
\text { job allowance }\end{array}$ \\
\hline Equipment & Rural job allowance provided \\
\hline Accommodation & Inadequate \\
\hline Contract & No provision of accommodation \\
\hline $\begin{array}{l}\text { Training } \\
\text { opportunities }\end{array}$ & Permanent (MoH) \\
\hline Types of support & Supportive supervision by health \\
& administrators \\
\hline
\end{tabular}

Which of these two jobs do you prefer?

\begin{tabular}{|lr|}
\hline \multicolumn{2}{|c|}{ Rural Job B } \\
\hline \begin{tabular}{l} 
Period of \\
assignment \\
\hline $\begin{array}{l}\text { Provision of a rural } \\
\text { job allowance }\end{array}$ \\
\hline Equipment
\end{tabular} Nears \\
\hline Accommodation & Adequate \\
\hline Contract & Accommodation provided \\
\hline $\begin{array}{l}\text { Training } \\
\text { opportunities }\end{array}$ & Temporary (Local) \\
\hline Types of support & Clinical advice and support from peer \\
& health professionals \\
\hline
\end{tabular}

$\square$ Rural Job A $\quad \square$ Rural Job B 


\section{Data analysis}

Data from the CE allowed ranking of the three jobs (jobs A, B, and current), as well as estimation of the probability of a particular job being best (ranked first) or worst (ranked last). We applied partial rank ordering when a respondent answered A (or B) in both questions, with only the best choice data used. This approach maximised the information obtained from the CE.

The data was analysed within the random utility maximisation (RUM) framework [21, 22], which assumes that in each choice $(t=1, \ldots, T)$, health professionals $(n=$ $1, \ldots, N)$ derive utility $\left(U_{n t j}\right)$ for a job $(j=1, \ldots, J)$ and choose the position yielding the highest utility, subject to errors $\left(\varepsilon_{n t j}\right)$. Assuming errors are independently and identically distributed as type 1 extreme values (IID EV1), the choice model takes the form of a multinomial logistic (MNL) regression.

The regression equation for physicians is:

$$
\begin{aligned}
U_{n t j}^{\text {PHYS }}= & \beta_{0} \text { CURRENT }_{n t j}+\beta_{1} \text { ALLOWANCE } \_1_{n t j} \\
& +\beta_{2} \text { ALLOWANCE_2 }_{n t j}+\beta_{3} \text { EQUIP }_{n t j} \\
& +\beta_{4} \text { ACCOMOD }_{n t j}+\beta_{5} \text { CONTRACT }_{1} 1_{n t j} \\
& +\beta_{6} \text { CONTRACT_ }_{n t j} \\
& +\beta_{7} \text { CONTRACT_ }_{n t j}+\beta_{8} \text { TRAINING }_{n t j} \\
& +\beta_{9} \text { PERIOD }_{n t j}+\varepsilon_{n t j}
\end{aligned}
$$

And the regression equation for non-physicians is:

$$
\begin{aligned}
U_{n t j}^{\text {NOPHYS }}= & \beta_{0} \text { CURRENT }_{n t j}+\beta_{1} \text { ALLOWANCE }_{n t j} \\
& +\beta_{2} \text { EQUIP }_{n t j}+\beta_{3} \text { ACCOMOD }_{n t j} \\
& +\beta_{4} \text { CONTRACT }_{1} 1_{n t j} \\
& +\beta_{5} \text { CONTRACT }_{2} 2_{n t j} \\
& +\beta_{6} \text { CONTRACT }_{n} 3_{n t j}+\beta_{7} \text { TRAINING }_{n t j} \\
& +\beta_{8} \text { PERIOD }_{n t j}+\beta_{9} \text { SUPPORT }_{1} 1_{n t j} \\
& +\beta_{10} \text { SUPPORT_ }_{2} 2_{n t j}+\varepsilon_{n t j}
\end{aligned}
$$

where all regression labels are defined in Table 2.

Willingness to stay (WTS) for marginal improvements in attributes, calculated as the ratio of the coefficient of interest to the negative of the coefficient on the assignment period attribute, was estimated. Associated confidence intervals were computed for all attributes using the delta method [23]. Overall WTS for a defined job was calculated as the sum of the WTS values for the job's various features.

Results from the MNL regression model were used to predict the probability of health workers remaining $\left(P_{n t j}\right)$ in a pre-defined (baseline) rural job $(j)$.

$$
P_{n t j}=\frac{\exp \left(U_{n t j}-\varepsilon_{n t j}\right)}{\sum_{j} \exp \left(U_{n t j}-\varepsilon_{n t j}\right)}
$$

The baseline scenario reflected current working conditions in the 'difficult' regions of Senegal: 4-year assignment period, no allowance, inadequate equipment at the health facility, no accommodation, temporary contract with the Health Ministry, no training, and no supportive supervision (non-physicians only). The retention rate for the baseline scenario was compared with retention rates for job contracts offering improvements in attributes.

\section{Results \\ Respondent characteristics}

The study included 55 physicians and 246 non-physicians. The physician group comprised 37 general practitioners (GPs) and 18 specialists, and the non-physician group comprised 153 nurses, 83 midwives and 11 specialised nurses. Of the physician respondents, $96.4 \%$ were male, while $60.2 \%$ of the non-physicians were female. The skewed gender distribution in physician respondents reflects actual patterns in the gender distribution of physicians working in the 'difficult' regions [7]. Health 'posts' are the smallest type of health facility operating in Senegal and are run by non-physicians. Consequently, health 'posts' did not have physician respondents. The amount of time spent working in rural/remote areas averaged 5.3 years for physician respondents (minimum less than 1 year; maximum 17 years; SD 4.3) and 7.4 years for non-physicians (minimum less than 1 year; maximum 38 years; SD 8.0). A range of contract types was used: $61.8 \%$ of physicians were permanently contracted government employees, $7.3 \%$ were annually contracted by the Health Ministry and 30.9\% hired either by health facilities or local authorities. For the non-physicians, $60.7 \%$ were permanent government employees, $17.4 \%$ were annually contracted by the Health Ministry, and $21.9 \%$ were locally hired.

\section{Preferences for job attributes}

All attributes, except professional support for non-physicians, were statistically significant, indicating that they impact on the probability of health professionals staying in a rural job (Table 3). The constant term for non-physicians was statistically significant with a negative coefficient, indicating a general preference not to remain in 'difficult' regions.

For physicians, a change in contract from temporary to permanent has the greatest impact on the probability of staying in a rural post, followed by the provision of training opportunities and the availability of equipment at a health facility. Similarly, for non-physicians, the provision of a permanent contract was the most valued attribute, followed by the availability of equipment and the provision of further training opportunities.

Both physicians and non-physicians ranked attributes relating to the functioning of health systems (availability of equipment at a health facility and the provision of supportive supervision) higher than some of the individual benefit attributes (provision of an allowance and accommodation). 
Table 3 Conditional Logit model

\begin{tabular}{|c|c|c|c|c|c|c|}
\hline & \multicolumn{3}{|l|}{ Physician } & \multicolumn{3}{|c|}{ Non-physician } \\
\hline & Coefficient & $\mathrm{SE}^{\mathrm{a}}$ & $P$ value & Coefficient & $\mathrm{SE}^{\mathrm{a}}$ & $P$ value \\
\hline \multicolumn{7}{|l|}{ 1. Model parameters } \\
\hline Current job condition & -0.093 & 0.124 & 0.454 & -0.442 & 0.066 & $<0.001$ \\
\hline Period & -0.195 & 0.026 & $<0.001$ & -0.172 & 0.016 & $<0.001$ \\
\hline Allowance & 0.382 & 0.125 & 0.002 & 0.267 & 0.060 & $<0.001$ \\
\hline Equipment & 0.732 & 0.166 & $<0.001$ & 0.577 & 0.066 & $<0.001$ \\
\hline Accommodation & 0.274 & 0.149 & 0.065 & 0.180 & 0.061 & $<0.001$ \\
\hline Temporary with $\mathrm{MoH}$ & -1.071 & 0.182 & $<0.001$ & -0.754 & 0.086 & 0.003 \\
\hline Contract with health facility & -1.849 & 0.259 & $<0.001$ & -1.520 & 0.097 & $<0.001$ \\
\hline Contract with local authorities & -1.873 & 0.202 & $<0.001$ & -1.459 & 0.113 & $<0.001$ \\
\hline Training & 0.955 & 0.137 & $<0.001$ & 0.346 & 0.064 & $<0.001$ \\
\hline Managerial support & - & - & - & 0.306 & 0.079 & $<0.001$ \\
\hline Professional support & - & - & - & 0.043 & 0.071 & 0.542 \\
\hline \multicolumn{7}{|l|}{ 2. Model statistics } \\
\hline Respondents & 55 & & & 246 & & \\
\hline Observations & 3909 & & & 17961 & & \\
\hline Log likelihood & -905.98 & & & -5053.37 & & \\
\hline Bayesian info criterion & 1886.40 & & & 10214.49 & & \\
\hline
\end{tabular}

${ }^{a}$ Robust standard errors adjusted for clustering on individual participants

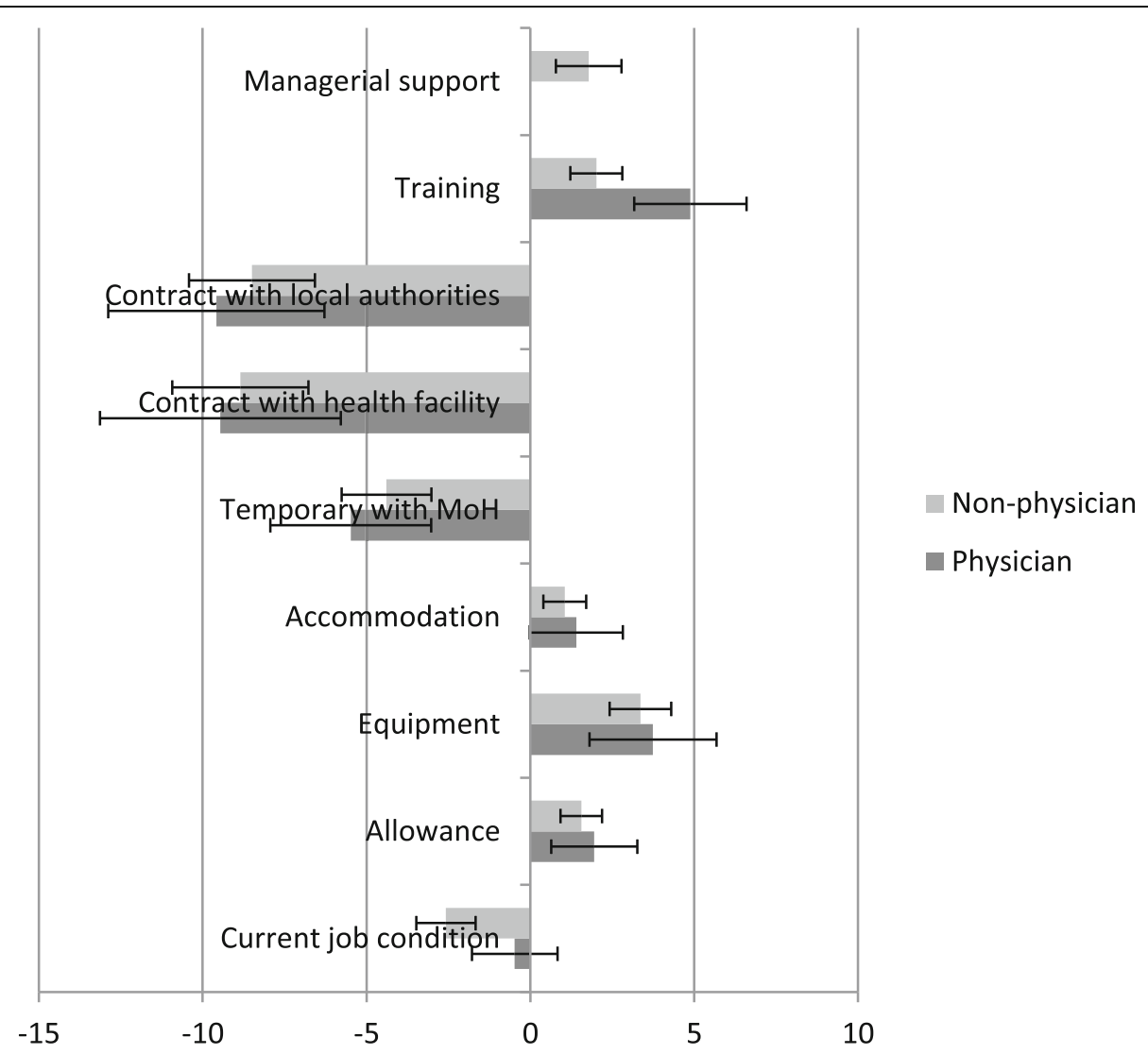

Fig. 3 Willingness to stay (WTS) estimates 
Willingness to stay (WTS) in 'difficult' regions

WTS for job improvements are shown in Fig. 3. WTS with improvements in the three most valued attributes (permanent contract, availability of equipment in health facilities and provision of further training opportunities) is 10.7 years for physicians and 5.4 years for non-physicians. However, if a permanent contract is not provided, and improvements only made to the availability of equipment and provision of training opportunities, the overall WTS is -0.3 years for physicians and -3.4 years for non-physicians. These negative figures suggest that, given the opportunity, both physicians and non-physicians would choose not to complete their assignments to the post.

\section{Probability of staying in 'difficult' regions}

Figure 4 presents retention probabilities for different policy options. The baseline (current) job contract has a $1.5 \%$ probability of retaining physicians in the position for the 4-year assignment period and $4.2 \%$ probability of retaining non-physicians in current positions. Provision of a permanent contract increases the probability of retaining a physician to $11.4 \%$ and non-physicians to $16.7 \%$. Availability of adequate equipment increases the retention rate to $6.1 \%$ for physicians and $12.3 \%$ for non-physicians. Further training opportunities increase the retention rate to $9.3 \%$ for physicians and $8.1 \%$ for non-physicians.

As with the WTS results, the retention probabilities suggest that policy reform affecting only a single attribute is unlikely to ensure health workers remain in 'difficult' regions, and retention policies should consider a combination of reforms. For instance, the retention rate for rural posts offering the three most preferred job conditions (permanent contract, availability of adequate equipment and further training opportunities) increases to $79.0 \%$ for physicians, an improvement of $77.5 \%$ points above the baseline, and 55.9\% for non-physicians, an improvement of $51.7 \%$ points above the baseline.

Combinations of individual benefit incentives and aspects of health system functioning were also considered. The retention rates for rural posts offering the three most preferred individual benefit incentives (i.e. permanent contract, further training opportunities and provision of an allowance) are estimated to be $65.1 \%$ for physicians and $40.5 \%$ for non-physicians. These retention rates increase to $89.0 \%$ for physicians and $79.9 \%$ for non-physicians if factors relating to the functioning of health systems are also improved (i.e. availability of basic equipment at health facilities for physicians, and availability of basic equipment and provision of supportive supervision for non-physicians). This finding supports the importance of improving health system functioning to improve that likelihood of health professionals remaining in rural posts.

\section{Discussion}

This study contributes to the literature on the retention of health workers in the rural areas of LMICs in a number of ways. The study contains two methodological originalities. Firstly, the study employed a BWS (Case 1) experiment to short-list factors identified in qualitative interview data and used a ranking score to determine policy options for inclusion in the CE. While most of the recent CE studies in LMICs have established attributes and assigned attribute levels using a qualitative approach, such as group discussions and in-depth interviews, this is the first CE in LMICs, and indeed CE in any context, which has applied BWS to finalise attributes after qualitative work was undertaken. BWS (Case 1) was a useful approach to reducing the number of attributes in a CE to a manageable level. Secondly, to ensure the

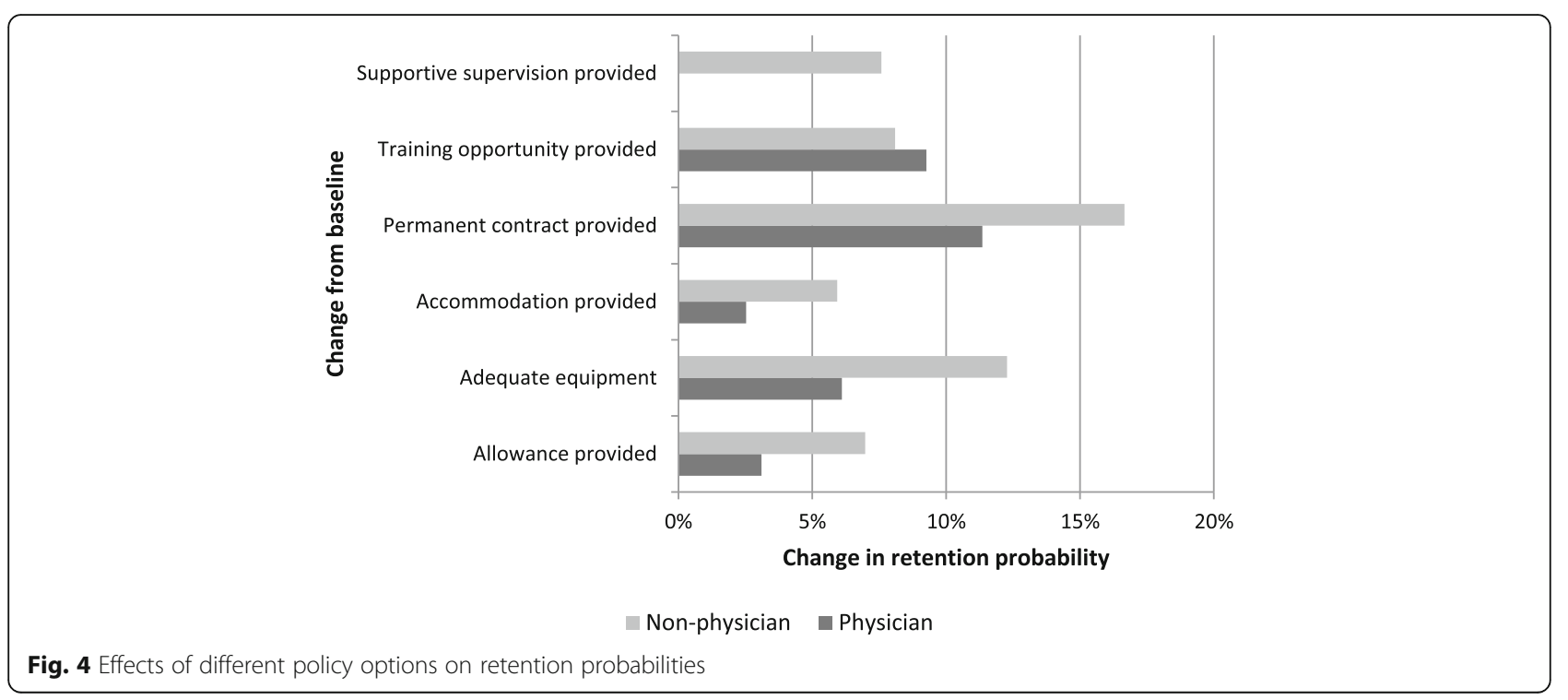


cultural acceptance and policy relevance of the attributes, WTS, instead of willingness to pay, was estimated using the period of assignment to determine trade-offs. This allowed estimation of how long respondents would be willing to stay in a rural post if there were improvements in other aspects of the contract attributes.

At the applied level, while CEs have been extensively used to investigate human resource issues in sub-Saharan Africa [24-31], the number of CEs in Western Africa is limited. Indeed, our study is only the third in Western Africa [32, 33], and the first in Senegal. Our results highlight the challenges of retaining the health workforce in rural areas of Senegal. The statistically significant negative constant term for non-physicians suggests that health workers are unlikely to want to remain in current roles in 'difficult' regions for the term of their posts. Policy makers must promptly respond to rural job retention issues, being mindful that policy reforms addressing single attribute are unlikely to improve retention rates. Retention policy should include a combination of reforms, including both individual incentives and factors relating to how health systems function.

To the authors' knowledge, this is the first CE study in LMICs that has included type of contract as an attribute, though two studies have included attributes on the number of years of service before obtaining a permanent post or promotion to permanent staff member [34, 35]. For both physicians and non-physicians, provision of a permanent contract was the factor which most affected the likelihood of job retention. In Senegal, while permanently contracted government workers, including public sector medical doctors and nurses, are employed and paid by the Ministry of Public Services, other health professionals are contracted annually by the Health Ministry [36]. Annually contracted health professionals do not receive government employee social benefit packages, such as pensions; however, the base salary for annually contracted health professionals is slightly higher than that of permanent health professionals. Renewal of annual contracts is unpredictable, depending on the availability of Health Ministry budget [36]. Given the key differences in the job conditions between the two types of contracts are the length of job security and the provision of social security entitlements, our study results suggest that respondents' value stability in employment and/or the entitlements associated with permanent employment.

In 2006, a program called "Plan Cobra" was introduced in Senegal, enabling the Health Ministry to hire health professionals using annual contracts. The plan aimed to address human resource shortages, particularly in rural areas, in a timelier manner than the lengthy process of hiring government workers through the Ministry of Public Services. While Plan Cobra used annual contracts to help distribute human resources to rural posts when it started in 2006 [9], over time, the nature of the contracts with the Health Ministry changed and, currently, annual contracts are used to employ health professionals regardless of geographical location. While in 2016, 48.9\% of public sector health professionals, including doctors, nurses and midwives, were permanent government employees [36], the proportion in our sample (healthcare professionals working in difficult regions) was around $60 \%$. Our results suggest that a short-term contract policy will not be effective in rural retention of healthcare professionals in the context of Senegal. Indeed, the Health Ministry has used the results from this study to introduce a rural assignment policy to recruit permanent staff from the pool of annually contracted healthcare professionals on the condition that they are assigned to rural posts. The results of this new policy intervention in Senegal require on-going monitoring. An 'emergency-hire' project for the recruitment of rural staff in Kenya saw most of those hired through the scheme leave rural areas after they were absorbed into the Government of Kenya's public service [37]. Such experiences in other contexts suggest that it is important to further examine the aspects of permanent contracts that facilitate the retention of healthcare professionals in rural areas.

Current evidence on effectiveness of monetary incentives (either in salary increases or bonus payments) on rural retention is mixed-while monetary incentives can enhance the motivation and retention of health professionals in rural and remote areas, provision of non-monetary incentives can be equally important $[13$, 38]. The results revealed that monetary incentives (rural or skills-based allowances) had a relatively small impact on retention in the study context. However, the study did not specify the level of the rural allowance to be provided. While a small rural allowance is likely to have little impact, a larger allowance may have a greater impact. Thus, further investigation is warranted. In addition, the qualitative study undertaken prior to the choice experiment indicated the importance of fair, transparent administration of salary and/or allowance payments [14], which also suggests that the study results on payment of allowances must be carefully interpreted and further investigation of various aspects associated with payment is required.

Our results show the importance of improving the functioning of health systems, which includes ensuring the availability of basic equipment at health facilities and the provision of supportive supervision. A number of studies have found that healthcare professionals strongly value the availability of equipment and infrastructure [39-41]. Given that less than $50 \%$ of the clinics in rural Senegal have access to basic equipment, and less than $30 \%$ of rural health facilities have access to electricity, water and sanitation [10], our results suggest that there will be difficulty in retaining health workers even if 
individual incentives are provided. Retention may be improved using innovative approaches at the community level if the government cannot find immediate solutions due to limited resource capacity [42].

Our results suggest a small proportion of staff want to see out their contracts under the current arrangements. This contradicts the actual longer periods that respondents have already served (averaging 5.3 and 7.4 years for physicians and non-physicians, respectively). Given the Senegalese context, where fiscal constraints can prevent the appointment of public sector health workers and where many health professionals are unemployed [36], this contradiction suggests employed healthcare professionals do not abandon their current posts, perhaps for fear of joining the ranks of the unemployed. Alternatively, those who have served long periods in difficult areas may be more able to cope, or have learned to cope, and so are more likely to stay even if their grievances are similar to those who have left the difficult areas. This requires further investigation.

Our CE was administered to those currently working in 'difficult' regions. It did not examine the preferences of those who had left rural posts or those studying to be health professionals. These groups may have different job preferences for work in rural posts than those interviewed in our study. Although this may limit the generalizability of the study results to all healthcare professionals in Senegal, a qualitative study undertaken prior to the $\mathrm{CE}$, which included interviews with those currently working in Dakar who had previously worked in 'difficult' regions, did not find differences in factors affecting job retention in 'difficult' regions between those in Dakar with experience in 'difficult' regions and those currently working in 'difficult' regions [14].

\section{Conclusion}

The study used a CE to elicit the job-related preferences of physician and non-physician health workers in 'difficult' regions of Senegal. For both groups, provision of a permanent contract, the availability of equipment in health facilities and the provision of training opportunities are the most valued rural work conditions. This is the first study to look at the impact of different contract types on the retention of health workers in rural areas. Contract type-either permanent or non-permanent-was found to be a key factor in rural job retention. Indeed, this result has led the Senegalese Health Ministry to introduce a rural assignment policy that recruits permanent staff from the pool of annually contracted healthcare professionals on the condition that the workers are assigned to rural posts. While our results suggest that this is a useful policy development, they also suggest that further policy development is required to ensure sufficient numbers of health workers in underserved areas to guarantee equitable access to quality healthcare for the people in those communities. A combination of individual incentives and health system improvements would facilitate the retention of health professionals in rural jobs.

\section{Abbreviations}

BWS: Best-worst scaling; CE: Choice experiment; GP: General practitioners; LMICs: Low- and middle-income countries; MNL: Multinomial logit (MNL); SE: Standard errors; UHC: Universal Health Coverage; WTS: Willingness to stay

\section{Acknowledgements}

The authors would like to express their profound gratitude to the fieldwork team and to the health professionals who responded to the survey questionnaire. Thanks also to four reviewers whose comments have improved the paper.

\section{Funding}

The study was funded through a Research Grant for International Health, H25-11, from the Ministry of Health, Welfare and Labour, Japan, and undertaken as part of the project Réseau Vision Tokyo 2010, funded by the Japan International Cooperation Agency.

\section{Availability of data and materials}

The datasets used and/or analysed in the study are available from the corresponding author on reasonable request.

\section{Authors' contributions}

NK, MR and AH developed the study design and data collection tools in consultation with MS, ID, MN and NF. MS supervised the field data collection in discussion with ID and $\mathrm{AH}$. $\mathrm{AH}, \mathrm{NK}$ and MR undertook the data analysis. All authors contributed to the preparation of the paper. All authors read and approved the final manuscript.

\section{Ethics approval and consent to participate}

The study received ethics approval from the ethics committee of the Ministère de la Santé et de l'Action Sociale du Sénégal, Dakar, Senegal. Study participants received information on the background, objectives and contribution of the study as well as details on how the collected information would be used. Prior to the survey, participants were asked to sign a consent form if they agreed to participate in the research.

Consent for publication

Not applicable.

\section{Competing interests}

The authors declare that they have no competing interests.

\section{Publisher's Note}

Springer Nature remains neutral with regard to jurisdictional claims in published maps and institutional affiliations.

\section{Author details}

'Department of Economics, Sophia University, 7-1 Kioi-cho, Chiyoda-ku, Tokyo 102-8554, Japan. ${ }^{2}$ Health Economics Research Unit, University of Aberdeen, Scotland, UK. ${ }^{3}$ Ministère de la Santé et de I'Action Sociale du Sénégal, Dakar, Senegal. ${ }^{4}$ National Centre for Global Health and Medicine, Tokyo, Japan.

Received: 29 April 2017 Accepted: 22 March 2019

Published online: 25 April 2019

\section{References}

1. Global Health Workforce Alliance. Health workforce 2030 - towards a global strategy on human resources for health [Synthesis paper]. Geneva: World Health Organization; 2015. 
2. World Health Organization. Health workforce requirements for universal health coverage and the sustainable development goals. Geneva: World Health Organization; 2016.

3. Araújoa EC, Maeda A. How to rectuit and retain health workers in rural and remote areas in developing countries: a guidance note. Washington, DC: World Bank; 2013.

4. World Bank: World development indicators. 2017

5. Buchan J, Couper ID, Tangcharoensathien V, Thepannya K, Jaskiewicz W, Perfilieva G, Dolea C. Early implementation of WHO recommendations for the retention of health workers in remote and rural areas. Bull World Health Organ. 2013;91(11):834-40.

6. Serneels P. Internal geographical imbalances: the role of human resources quality and quantity. In: Culyer AJ, editor. Encycopedia of Health Economics. Amsterdam: Elsevier; 2014.

7. Ministère de la Santé et de l'Action Sociale du Sénégal. Profil des Ressources Humaines du Sénégal. Dakar: Direction des Ressources Humaines, Ministère de la Santé et de l'Action Sociale du Sénégal; 2012.

8. World Bank: World development indicators. 2015.

9. Zurn P, Codjia L, Sall FL, Braichet JM. How to recruit and retain health workers in underserved areas: the Senegalese experience. Bull World Health Organ. 2010:88(5):386-9.

10. World Bank. Service delivery indicators: Senegal. Washington, DC: World Bank; 2013.

11. Ministère de la Santé et de l'Action Sociale du Sénégal. Atelier de Partage et de Validation des Stratégies de Couverture des Zones Difficiles en Personnels de Santé: Rapport de Synthèse. Dakar: Direction des Ressources Humaines, Ministère de la Santé et de l'Action Sociale du Sénégal; 2010.

12. De Bekker-Grob E, Ryan M, Gerard K. Discrete choice experiments in health economics: a review of the literature. Health Econ. 2012;21(2):145-72.

13. Mandeville KL, Lagarde M, Hanson K. The use of discrete choice experiments to inform health workforce policy: a systematic review. BMC Health Serv Res. 2014;14:367.

14. Nagai M, Fujita N, Diouf IS, Salla M. Retention of qualified healthcare workers in rural Senegal: lessons learned from a qualitative study. Rural Remote Health. 2017;17(3):4149.

15. Flynn TN, Louviere JJ, Peters TJ, Coast J. Best-worst scaling: what it can do for health care research and how to do it. J Health Econ. 2007:26(1):171-89.

16. Louviere J, Lings I, Islam T, Gudergan S, Flynn T. An introduction to the application of (case 1) best-worst scaling in marketing research. Int J Res Mark. 2013;30(3):292-303

17. Ryan M, Kolstad J, Rockers $P$, Dolea C. User guide with case studies: how to conduct a discrete choice experiment for health workforce recruitment and retention in remote and rural areas. Washington, DC: World Bank; 2012.

18. Ryan M, Gerard K, Amaya-Amaya M, editors. Using discrete choice experiments to value health and health care. Dordrecht: Springer; 2008.

19. Louviere J, Hensher D, Swait J. Stated choice methods: analysis and application, first edition edn. Cambridge: Cambridge University Press; 2000

20. Bennett J, Birol E, editors. Choice experiments in developing countries: implementation, challenges and policy implications. Cheltenham and Northampton: Edward Elgar; 2010.

21. McFadden D. Conditional logit analysis of qualitative choice behavior. In: Zarembka P, editor. Frontiers in econometrics. edn New York: Academic Press; 1974. p. 105-42.

22. Manski C. The structure of random utility models. Theor Decis. 1977;8(3):229-54.

23. Hole AR. WTP: Stata module to estimate confidence intervals for WTP measures; 2007

24. Takemura T, Kielmann K, Blaauw D. Job preferences among clinical officers in public sector facilities in rural Kenya: a discrete choice experiment. Human Resources for Health. 2016;14:1.

25. Mandeville KL, Ulaya G, Lagarde M, Muula AS, Dzowela T, Hanson K. The use of specialty training to retain doctors in Malawi: a discrete choice experiment. Soc Sci Med (1982). 2016;169:109-18.

26. Honda A, Vio F. Incentives for non-physician health professionals to work in the rural and remote areas of Mozambique--a discrete choice experiment for eliciting job preferences. Hum Resour Health. 2015;13:23.

27. Rockers PC, Jaskiewicz W, Wurts L, Kruk ME, Mgomella GS, Ntalazi F, Tulenko $K$. Preferences for working in rural clinics among trainee health professionals in Uganda: a discrete choice experiment. BMC Health Serv Res. 2012;12:212.

28. Kolstad J. How to make rural jobs more attractive to health workers Findings from a discrete choice experiment in Tanzania. Health Econ. 2011; 20(2):196-211
29. Kruk ME, Johnson JC, Gyakobo M, Agyei-Baffour P, Asabir K, Kotha SR, Kwansah J, Nakua E, Snow RC, Dzodzomenyo M. Rural practice preferences among medical students in Ghana: a discrete choice experiment. Bull World Health Organ. 2010;88(5):333-41.

30. Mangham L, Hanson K. Employment preferences of public sector nurses in Malawi: results from a discrete choice experiment. Tropical Med Int Health. 2008;13(12):1433-41.

31. Hanson K, Jack W. Health worker preferences for job attributes in Ethiopia: results from a discrete choice experiment. Washington, DC: World Bank; 2008

32. Robyn PJ, Shroff Z, Zang OR, Kingue S, Djienouassi S, Kouontchou C, Sorgho G. Addressing health workforce distribution concerns: a discrete choice experiment to develop rural retention strategies in Cameroon. Int J Health Policy Manage. 2015;4(3):169-80.

33. Yaya Bocoum F, Koné E, Kouanda S, Yaméogo WME, Bado AR. Which incentive package will retain regionalized health personnel in Burkina Faso: a discrete choice experiment. Hum Resour Health. 2014;12(Suppl 1):S7.

34. Miranda JJ, Diez-Canseco F, Lema C, Lescano AG, Lagarde M, Blaauw D, Huicho L. Stated preferences of doctors for choosing a job in rural areas of Peru: a discrete choice experiment. PLoS One. 2012;7(12):e50567.

35. Rockers PC, Jaskiewicz W, Kruk ME, Phathammavong O, Vangkonevilay $P$, Paphassarang C, Phachanh IT, Wurts L, Tulenko K. Differences in preferences for rural job postings between nursing students and practicing nurses: evidence from a discrete choice experiment in Lao People's Democratic Republic. Hum Resour Health. 2013;11:22.

36. Réseau Vision Tokyo 2010. L'analyse situationnelle des ressources humaines en santé des membres membres du Réseau Vision Tokyo 2010. Tokyo: Réseau Vision Tokyo 2010; 2017.

37. Vindigni SM, Riley PL, Kimani F, Willy R, Warutere P, Sabatier JF, Kiriinya R, Friedman M, Osumba M, Waudo AN, et al. Kenya's emergency-hire nursing programme: a pilot evaluation of health service delivery in two districts. Hum Resour Health. 2014;12(1):16.

38. Lagarde M, Blaauw D. A review of the application and contribution of discrete choice experiments to inform human resources policy interventions. Hum Resour Health. 2009:7(1):62.

39. Smitz M-F, Witter S, Lemiere C, Eozenou PH-V, Lievens T, Zaman RU, Engelhardt K, Hou X. Understanding health workers' job preferences to improve rural retention in Timor-Leste: findings from a discrete choice experiment. PLoS One. 2016;11(11):e0165940.

40. Vujicic M, Shengelia B, Alfano M, Thu HB. Physician shortages in rural Vietnam: using a labor market approach to inform policy. Soc Sci Med. 2011;73(7):970-7.

41. Ageyi-Baffour P, Rominski S, Nakua E, Gyakobo M, Lori JR. Factors that influence midwifery students in Ghana when deciding where to practice: a discrete choice experiment. BMC Med Educ. 2013;13:64.

42. Alhassan RK, Nketiah-Amponsah E, Spieker N, Arhinful DK, Rinke de Wit TF. Assessing the impact of community engagement interventions on health worker motivation and experiences with clients in primary health facilities in Ghana: a randomized cluster trial. PLoS One. 2016;11(7):e0158541.

Ready to submit your research? Choose BMC and benefit from:

- fast, convenient online submission

- thorough peer review by experienced researchers in your field

- rapid publication on acceptance

- support for research data, including large and complex data types

- gold Open Access which fosters wider collaboration and increased citations

- maximum visibility for your research: over $100 \mathrm{M}$ website views per year

At BMC, research is always in progress.

Learn more biomedcentral.com/submissions 